\title{
Aeroacoustic and Performance Simulations of a Test Scale Open Rotor
}

\author{
Russell W. Claus
}

Glenn Research Center, Cleveland, Ohio 


\section{NASA STI Program . . . in Profile}

Since its founding, NASA has been dedicated to the advancement of aeronautics and space science. The NASA Scientific and Technical Information (STI) program plays a key part in helping NASA maintain this important role.

The NASA STI Program operates under the auspices of the Agency Chief Information Officer. It collects, organizes, provides for archiving, and disseminates NASA's STI. The NASA STI program provides access to the NASA Aeronautics and Space Database and its public interface, the NASA Technical Reports Server, thus providing one of the largest collections of aeronautical and space science STI in the world. Results are published in both non-NASA channels and by NASA in the NASA STI Report Series, which includes the following report types:

- TECHNICAL PUBLICATION. Reports of completed research or a major significant phase of research that present the results of NASA programs and include extensive data or theoretical analysis. Includes compilations of significant scientific and technical data and information deemed to be of continuing reference value. NASA counterpart of peer-reviewed formal professional papers but has less stringent limitations on manuscript length and extent of graphic presentations.

- TECHNICAL MEMORANDUM. Scientific and technical findings that are preliminary or of specialized interest, e.g., quick release reports, working papers, and bibliographies that contain minimal annotation. Does not contain extensive analysis.

- CONTRACTOR REPORT. Scientific and technical findings by NASA-sponsored contractors and grantees.
- CONFERENCE PUBLICATION. Collected papers from scientific and technical conferences, symposia, seminars, or other meetings sponsored or cosponsored by NASA.

- SPECIAL PUBLICATION. Scientific, technical, or historical information from NASA programs, projects, and missions, often concerned with subjects having substantial public interest.

- TECHNICAL TRANSLATION. Englishlanguage translations of foreign scientific and technical material pertinent to NASA's mission.

Specialized services also include creating custom thesauri, building customized databases, organizing and publishing research results.

For more information about the NASA STI program, see the following:

- Access the NASA STI program home page at http://www.sti.nasa.gov

- E-mail your question to help@sti.nasa.gov

- Fax your question to the NASA STI Information Desk at 443-757-5803

- Phone the NASA STI Information Desk at 443-757-5802

- Write to: STI Information Desk NASA Center for AeroSpace Information 7115 Standard Drive Hanover, MD 21076-1320 


\section{Aeroacoustic and Performance Simulations of a Test Scale Open Rotor}

Russell W. Claus

Glenn Research Center, Cleveland, Ohio

Prepared for the

48th Joint Propulsion Conference and Exhibit

cosponsored by the AIAA, ASME, SAE, and ASEE

Atlanta, Georgia, July 30-August 1, 2012

National Aeronautics and

Space Administration

Glenn Research Center

Cleveland, Ohio 44135 


\section{Acknowledgments}

This research was supported by the Subsonic Fixed-Wing element of the Fundamental Aeronautic Program at NASA. The author would like to further acknowledge the assistance of Ed Envia, Tim Beach, Dale Van Zante, Bill Haller and Chris Miller at the NASA Glenn Research Center.

This report is a formal draft or working paper, intended to solicit comments and ideas from a technical peer group.

This report contains preliminary findings, subject to revision as analysis proceeds.

Trade names and trademarks are used in this report for identification only. Their usage does not constitute an official endorsement, either expressed or implied, by the National Aeronautics and Space Administration.

This work was sponsored by the Fundamental Aeronautics Program at the NASA Glenn Research Center.

Level of Review: This material has been technically reviewed by technical management.

Available from

NASA Center for Aerospace Information 7115 Standard Drive

Hanover, MD 21076-1320
National Technical Information Service 5301 Shawnee Road Alexandria, VA 22312 


\title{
Aeroacoustic and Performance Simulations of a Test Scale Open Rotor
}

\author{
Russell W. Claus \\ National Aeronautics and Space Administration \\ Glenn Research Center \\ Cleveland, Ohio 44135
}

\begin{abstract}
This paper explores a comparison between experimental data and numerical simulations of the historical baseline F31/A31 open rotor geometry. The experimental data were obtained at the NASA Glenn Research Center's Aeroacoustic facilty and include performance and noise information for a variety of flow speeds (matching take-off and cruise). The numerical simulations provide both performance and aeroaucostic results using the NUMECA's Fine-Turbo analysis code. A non-linear harmonic method is used to capture the rotor/rotor interaction.
\end{abstract}

\section{Nomenclature}

$\begin{array}{ll}\text { BPF } & \text { blade passage frequency } \\ \text { BPF }^{a} & \text { aft blade passage frequency } \\ \text { BPF }^{f} & \text { forward blade passage frequency } \\ \text { BPR } & \text { by pass ratio } \\ \text { FWH } & \text { Ffowcs Williams Hawkings } \\ \text { GRC } & \text { NASA Glenn Research Center } \\ \text { Nc } & \text { corrected rotational speed, rpm } \\ \text { NLH } & \text { non-linear harmonic }\end{array}$

\section{Introduction}

Due to its high propulsive efficiency an open rotor gas turbine engine has the potential to minimize specific fuel consumption in a new generation of transport aircraft (Ref. 1). Other concepts, such as the ultra-high bypass fan (BPR > 10) offer improved fuel burn performance with low noise, but their propulsive efficiency lags behind the open rotor by a significant margin. The greatest weakness of the open rotor concept was illustrated during the flight testing: high levels of tonal noise.

NASA supported substantial research into the open rotor concept during the 1980s that was terminated after the flight testing of prototypes on a Boeing 727 and a McDonnell Douglas MD 80 (Ref. 2). This early effort served to illustrate the potential of the concept, but did not resolve noise and other concerns. The F31 /A31 geometry studied in this report is an example of the geometries explored during this time period. The blades were remanufacturered from original geometry coordinates and tested at the NASA Glenn Research Center (GRC) in collaboration with General Electric (Ref. 3). The referenced report provides an open dataset that can be used to validate numerical tools and provides a general technology baseline reflecting the previous open rotor research.

This report compares experimental data to numerical simulations of the flow field matching conditions in GRC's aeroacoustic testing facilty. The intent is to explore the predictive accuracy of steady-state analysis for the performance and acoustics of the F31/A31 geometry. Previous studies indicated the potential to capture acoustic information from numerical analysis (Ref. 4). Envia et al., (Ref. 5) used time-accurate simulations for the F31/A31 flowfield to make reasonable acoustic estimates of tonal noise on the F31/A31 blades. The general expectation is that a steady-state analysis employing a non-linear harmonic (NLH) model for the rotor/rotor interface may be able to estimate tonal noise levels 
at a reduced computational cost and with a shorter turn-around. This report will document the performance level predicted using NLH and test the accuracy of its acoustic predictions.

\section{Computation Approach}

Numerical simulations solved the Reynold's Averaged Navier-Stokes equations using the Numeca's Fine-Turbo (Ref. 6) suite of codes. This software has a fully integrated suite of tools that enable rapid mesh generation, domain decomposition, flow solver and visualization. The mesh generation can be controlled through a series of application specific wizards that tailor the grid topology and optimization to the application-specific geometry. Commonly, the defaults for the mesh generation provide good mesh characteristics, however, adjustments were made using available manual controls. The operating blade shapes were provided (Ref. 3) in IGES format for nominal take-off blade pitch. Cruise blade orientations were generated using the blade rotation features in Fine Turbo.

Fine-turbo employs a variety of possible rotor/stator interface techniques and differing turbulence models. In this study, the steady-state options were used including the Spalart-Almos turbulence model, the mixing plane approximation and the NLH model. NLH models the unsteadiness of the blade wakes assuming the flow is temporally periodic. The periodic disturbances can then be decomposed as fundamental frequencies of the blade passage frequency (BPF). Deterministic stresses can then be solved for using a time-marching spectral method representing one upstream and one downstream flow pertabation. These time-marching equations are solved until a steady-state is achieved. In this study, each perturbation was represented by three frequencies, although test calculations where examined with five frequencies that indicated no significant change in results.

A typical calculation was started by obtaining a fully-converged mixing-plane solution. This result was then used as the starting point for the NLH calculation. The NLH calculation would usually converge only about one or two additional-order of magnitudes on the global residual, so additional parameters would be monitored to ensure full convergence.

The acoustic signature of an open rotor is typically dominated by tonal noise mechanisms (Ref. 3). These noise sources arise due to steady and unsteady pressure forces with the unsteady forces much smaller than the steady forces. A single propeller typically generates tonal noise related to the BPF and its higher harmonics. The sound pressure level associated with the higher harmonics typically decreases rapidly at higher frequencies for a single rotor. With an open rotor, the interactions between the two blades can lead to higher sound pressure levels at the higher interaction tones. Indeed, for the experiment used in this report, the higher order harmonic associated with a tone twice the forward BPF and one times the aft BPF generated higher sound levels than the primary BPFs.

The acoustics were calculated using a post-processing module in Fine-Turbo. The module solved the Ffowcs Williams Hawkings (FWH) equations modeling acoustic propogation. Acoustic sources were selected following the approach suggested in Reference 4. An acoustic observer was postioned to match the locations of microphone in the experiment. The periodicity of the acoustic signal was estimated as $1 /\left(\mathrm{BPF}^{\mathrm{f}}-\mathrm{BPF}^{\mathrm{a}}\right)$ or $\sim 0.00452 \mathrm{~s}$. Typically 128 time periods captured the primary blade harmonics and the related interaction tones.

Figure 1 illustrates the general flow domain used in the reported calculations. The inflow boundary is located upstream of the test pylon and extends to the end of the test article. The radial domain extends to six times the radius of the rotors for take-off conditions. Cruise calculations were made with an extended radial domain including eight times the rotor radius. External boundary conditions (static conditions) were specified at the domain limits to match the appropriate test conditions. Inflow boundary conditions specified total quantities at standard day conditions. 

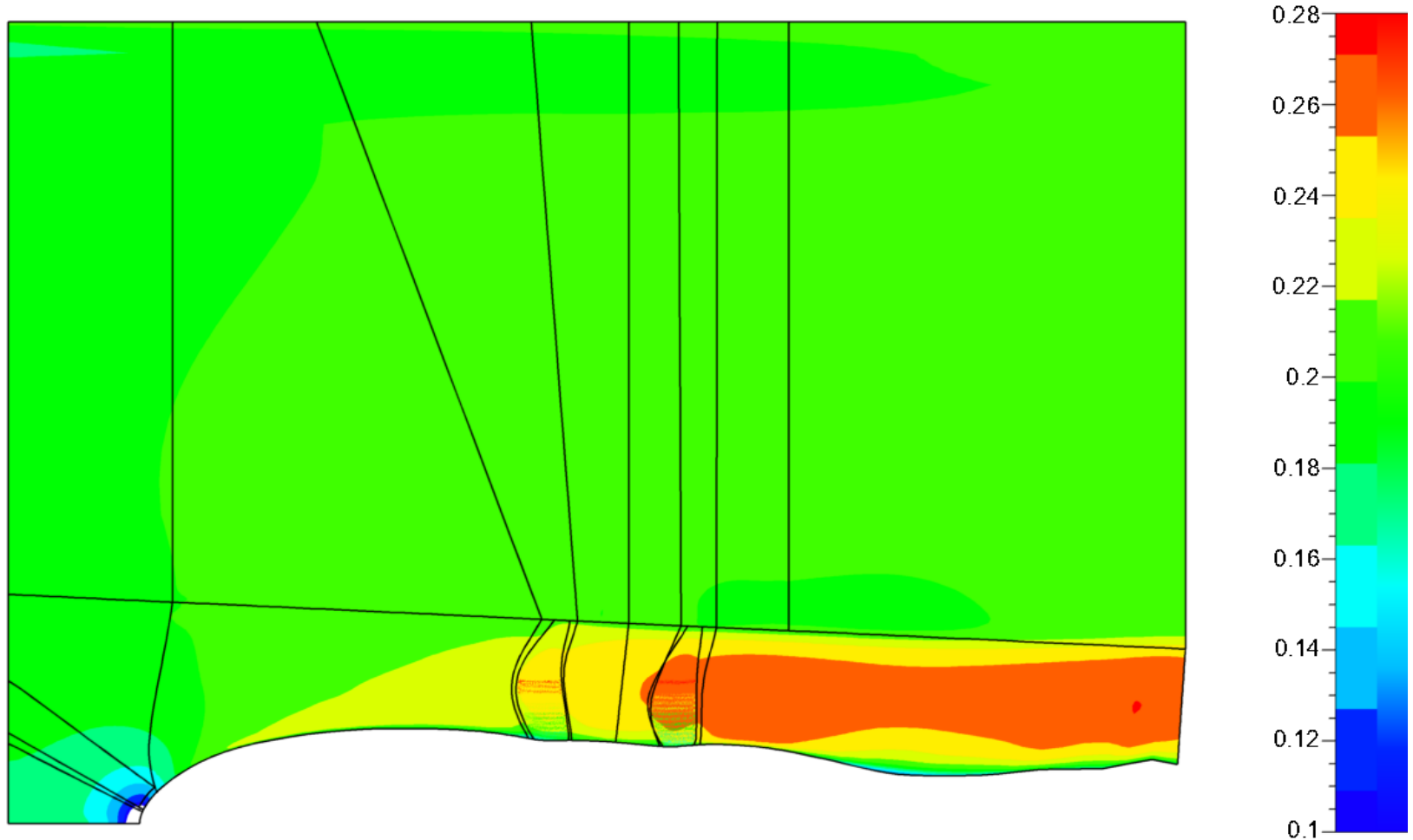

Figure 1.-Circumferentially averaged Mach number for a typical open rotor at take-off conditions, rpm 3395 . Flow is left-to-right.

Fine-turbo employs a multi-block domain decompostion that was meshed to provide good resolution for both acoustic and flow fields. Mesh characteristics were good with aspect ratios typically under 500, expansion ratios under 2, angular deviation under 20 and skewness above 30 . The mesh region where the aspect ratio approached 500 were less critical portions for the flow field (i.e., far field).

Figure 2(a) illustrates the mesh used around the rotor blades at the mid-span location. Figure 2(b) illustrates the mesh near the trailing edge of the forward rotor. The mesh density was more than needed for aerodynamic force representation and was selected to provide the best possible near-field resolution for the acoustic post-processing.

Table 1 displays the various calculation details. The mesh used for take-off conditions was reduced for cruise comparisons as no acoustic data were recorded.

TABLE 1.-MESH DENSITIES USED IN VARIUOS CALCULATIONS

\begin{tabular}{|l|c|c|c|c|c|}
\hline Operating point & Forward row mesh & Aft rotor mesh & Row 1 farfield & Row 2 farfield & Total \\
\hline Cruise & 1738731 & 1693467 & 2144870 & 1917110 & 7923859 \\
\hline Take-off & 3817287 & 4079727 & 3893370 & 3807310 & 16482067 \\
\hline
\end{tabular}




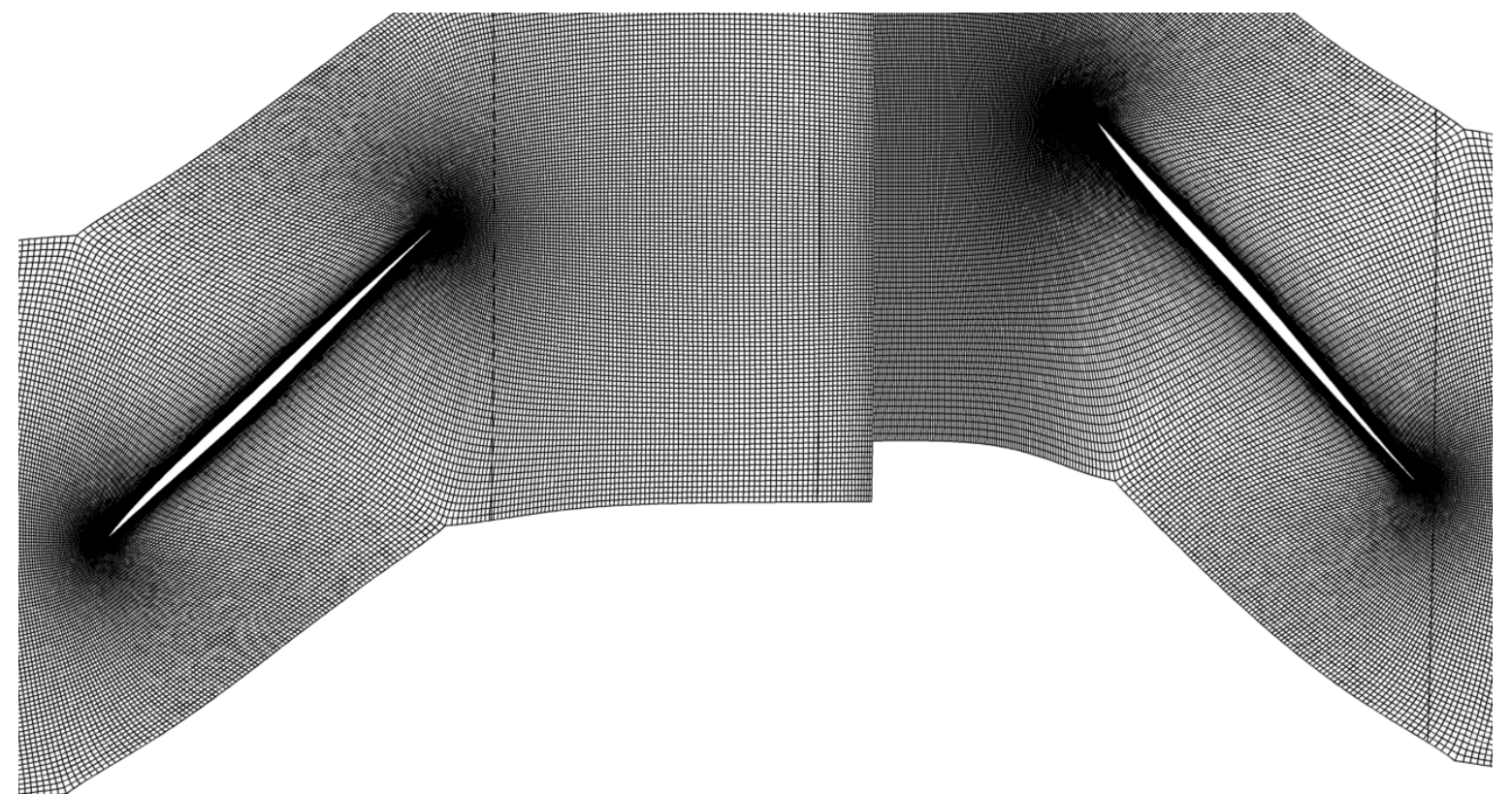

(a)

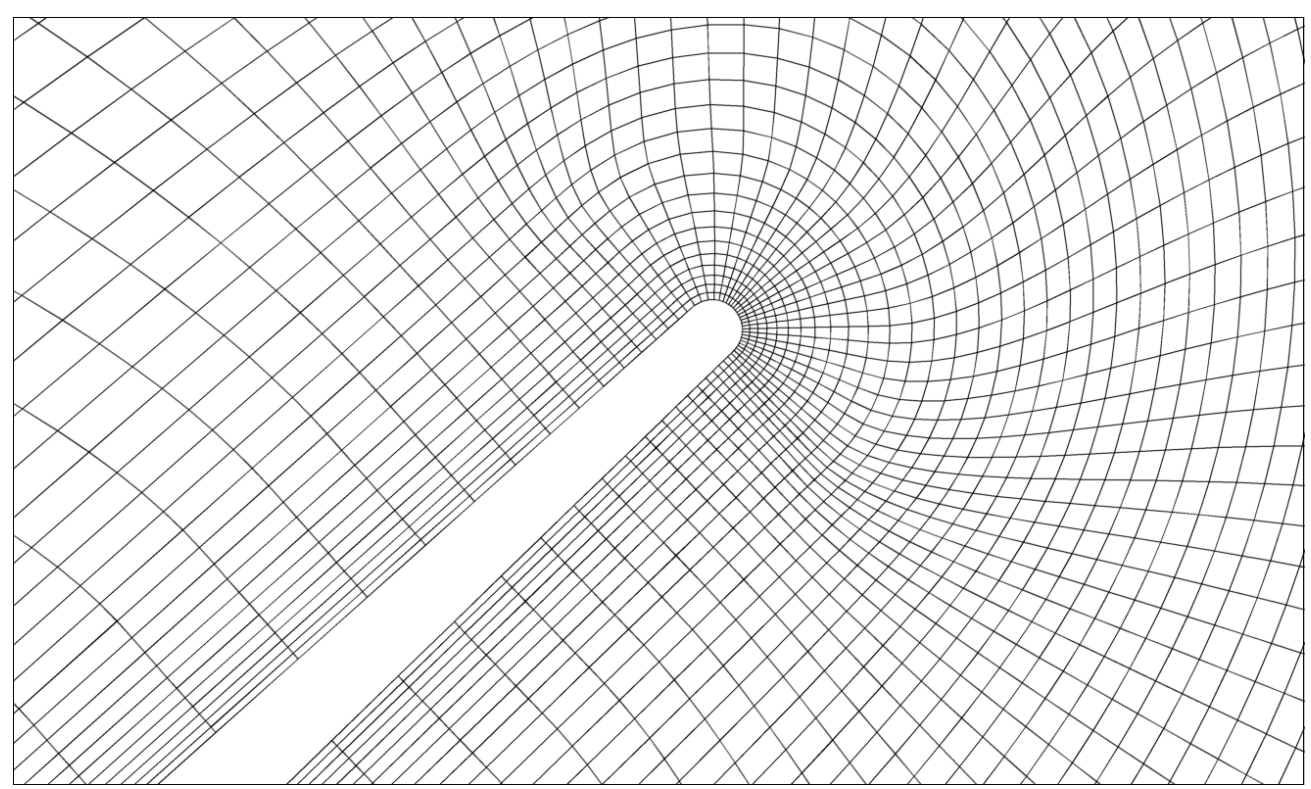

(b)

Figure 2.-(a). Overview of the mesh used around the rotors. Blades are displayed in take-off pitch at 50 percent span. (b) Mesh refinement around the trailing edge of the forward rotor at mid-span. 


\section{Results}

The F31/A31 geometry was analyzed at two different operating conditions, nominally related to takeoff and cruise flight speeds. The take-off conditions (Mach no. $\sim 0.2$ ) had experimentally-measured acoustic data that enabled comparison with the Fine-Turbo FWH acoustic calculations.

\section{Take-Off Condition}

Figure 3 displays open rotor thrust levels versus corrected rpm $(\mathrm{Nc})$ for both experimental data and numerical simulations. At all rotational speeds, the numerical calculations are slightly higher than experiment. In general, the rotor thrust is well predicted across the range of rotational speeds for take-off flow conditions.

Figure 4 displays a comparison of acoustic sound levels versus fundamental BPFs and interaction tones for the F31/A31 geometry at take-off conditions. The microphone location was at $90^{\circ}$ to the aft rotor and $1.5 \mathrm{~m}$ from the centerline. The simulation employed a corrected rpm of 6625 versus 6598 experimentally. The primary BPFs are labeled 10 and 12 (corresponding to the number of blades per row) with higher order harmonics such as 20 or 24 (2 time the primary BPF) and the interaction tones displayed. The experiment indicates that the highest sound level is produced by an interation tone (32twice the $\mathrm{BPF}^{\mathrm{a}}$ plus one times the $\mathrm{BPF}^{\mathrm{f}}$ ) at about $110 \mathrm{~dB}$. The simulations over-predict sound levels for several tones including the primary BPFs and the highest interaction tone, 32. The over-prediction is just a few decibels. Several tones are under-predicted, but overall, sound pressure levels are reasonably wellpredicted, with under-prediction at the higher tones.

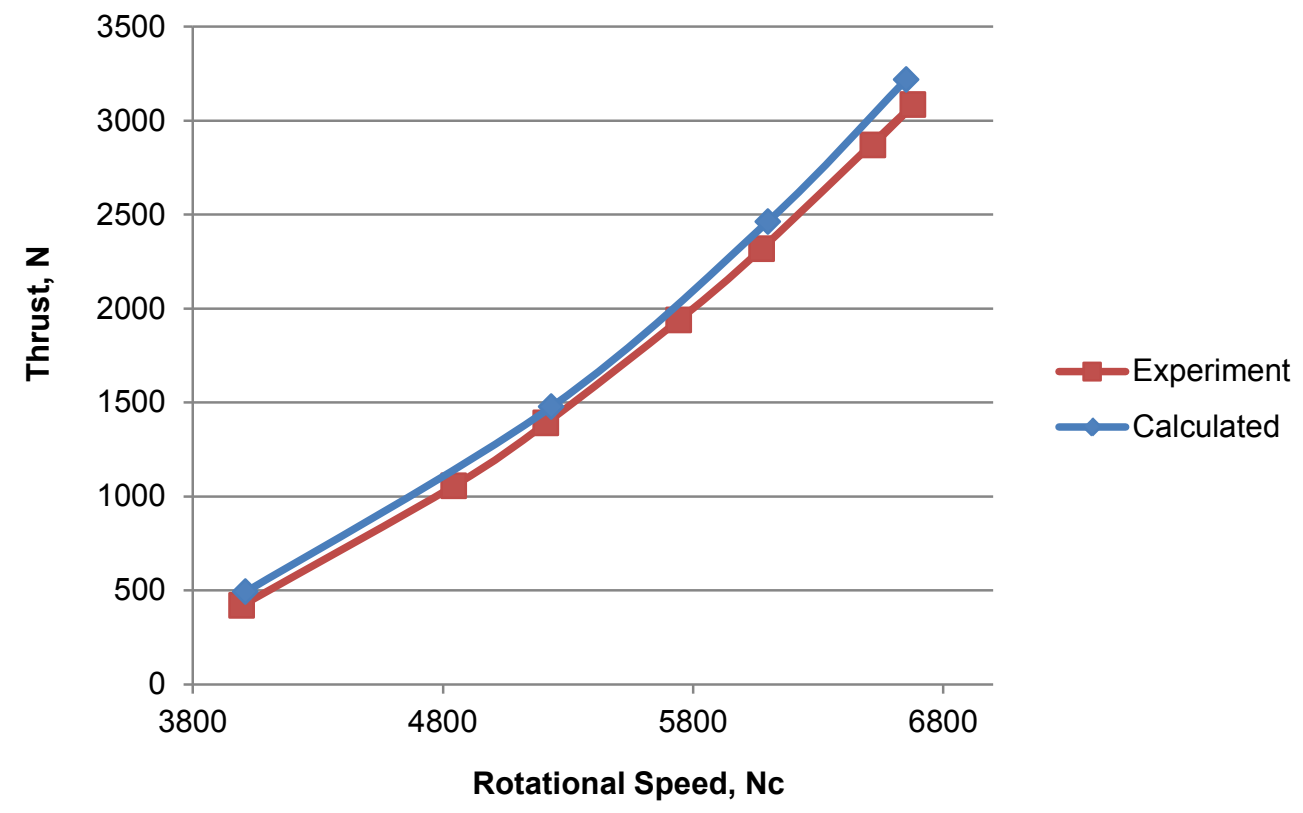

Figure 3.-Thrust versus rotational speed at take-off conditions. 


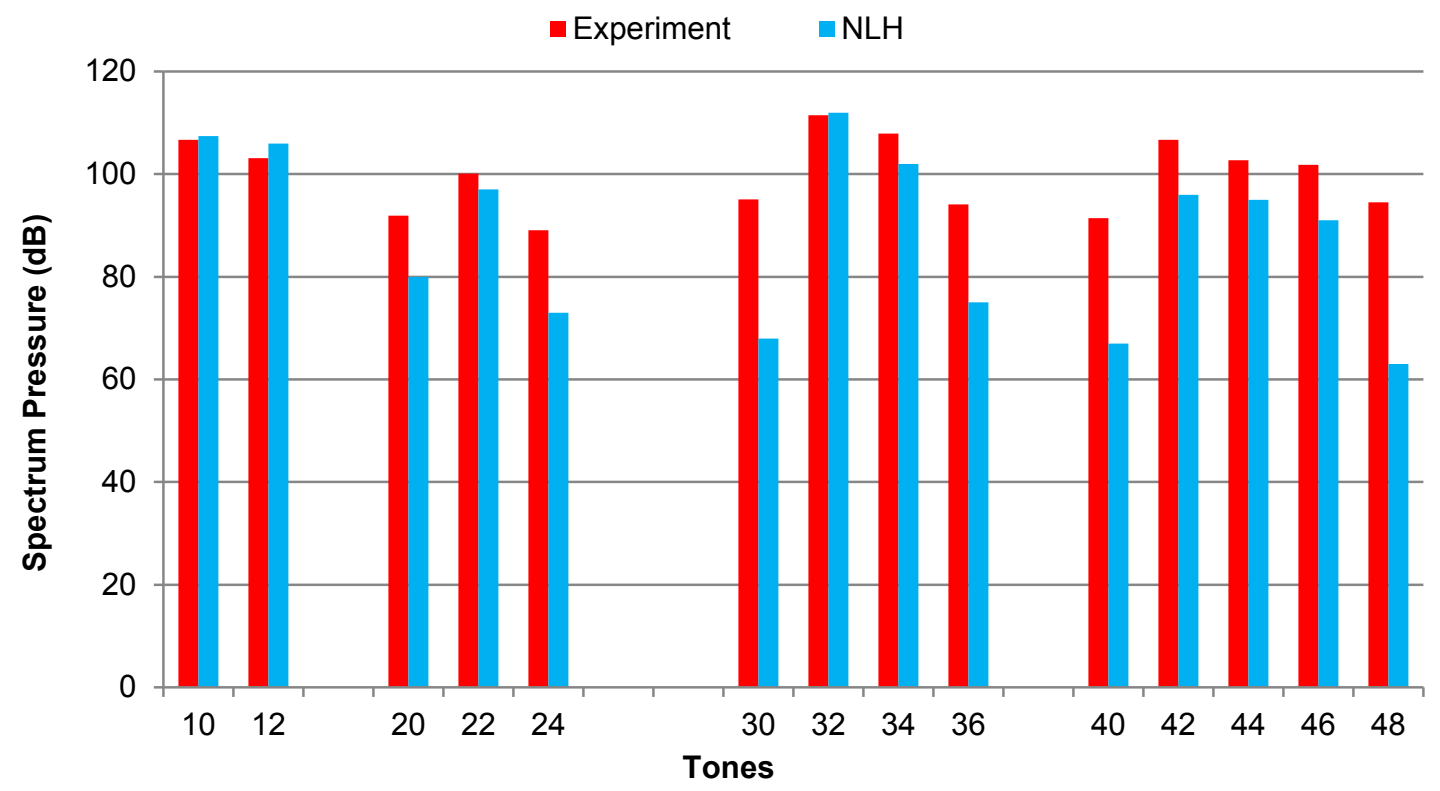

Figure 4.-Acoustic sound pressure levels versus fundamental and interaction tones for experiment and calculation. Front rotor tones; $12^{*} n$ where $n=1,2,3, \ldots$ (where $n=1$ is the fundamental for the front rotor). Aft rotor tones: $=10^{*} n$ where $n=1,2,3, \ldots$ (where $n=1$ is the fundamental for the aft rotor). Interaction tones: $12^{*} n+10^{*} m$ (where $n=1,2,3, \ldots$ and $m=1,2,3, \ldots)$.

The acoustic calculations made for Figure 3 and Figure 4 are at the limits of current computing capabilities for approximately 12 computing nodes, e.g., approximately 40 wall clock hours and 80 GBs of memory. Mesh refinement studies had indicated that this mesh resolution was excessive for performance data (i.e., thrust), but thought to be important for acoustic predictions. To test this assumption, the mesh was reduced in resolution by a factor of 2 in each coordinate direction and the NLH model was reduced to two frequencies representing each perturbation. This resulted in a calculation that could be made on a single node computer with $3 \mathrm{~GB}$ of memory in less than $12 \mathrm{hr}$. Figure 5(a) displays the acoustic results from this calculation. The level of agreement seen in the calculations indicates that the acoustic calculation was not as sensitive as expected for the $90^{\circ}$ angle. The mesh sensitivity should be greatest at the highest frequencies. Figure 5(b) displays a comparison between the fine and course mesh calculations at the higher frequency tones.

Figure 5(c) displays the results of the fine and coarse mesh calculations for a microphone location of $140^{\circ}$ and radial distance of $1.5 \mathrm{~m}$. These results display a clear mesh dependency that is not seen at the $90^{\circ}$ location. Here the additional mesh resolution is clearly beneficial.

While the agreement with data for the two acoustic calculations is encouraging, this should be viewed with caution. Envia (Ref. 5) indicates that acoustic estimates beyond the NLH simulation harmonicsthree times the fundamental for both the front and aft rotor on the fine mesh-should be unreliable. Acoustic predictions at tones above 30 or 36, such as the tones seen in Figure 5(b), should be expected to be less accurate. However, these calculations do not display this trend. This issue will be the focus of future studies. 


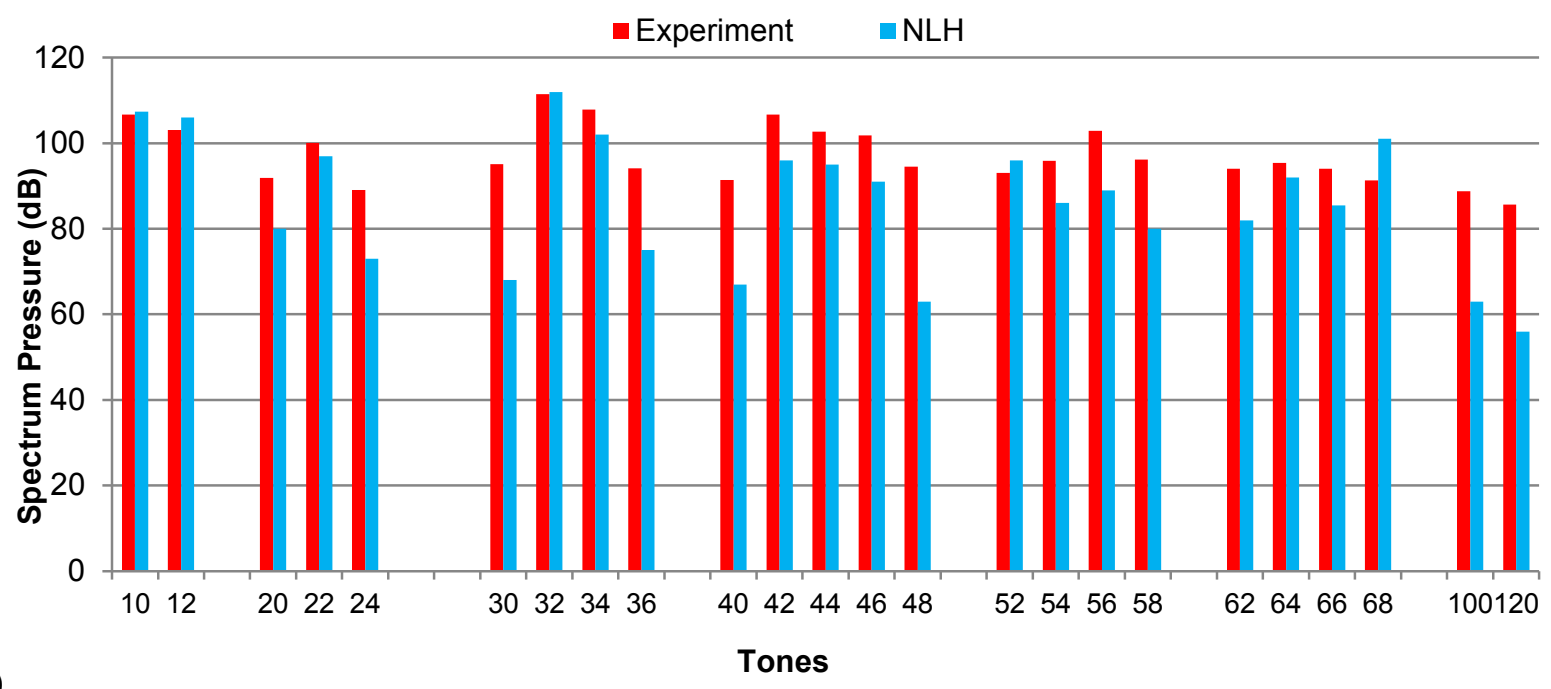

(a)
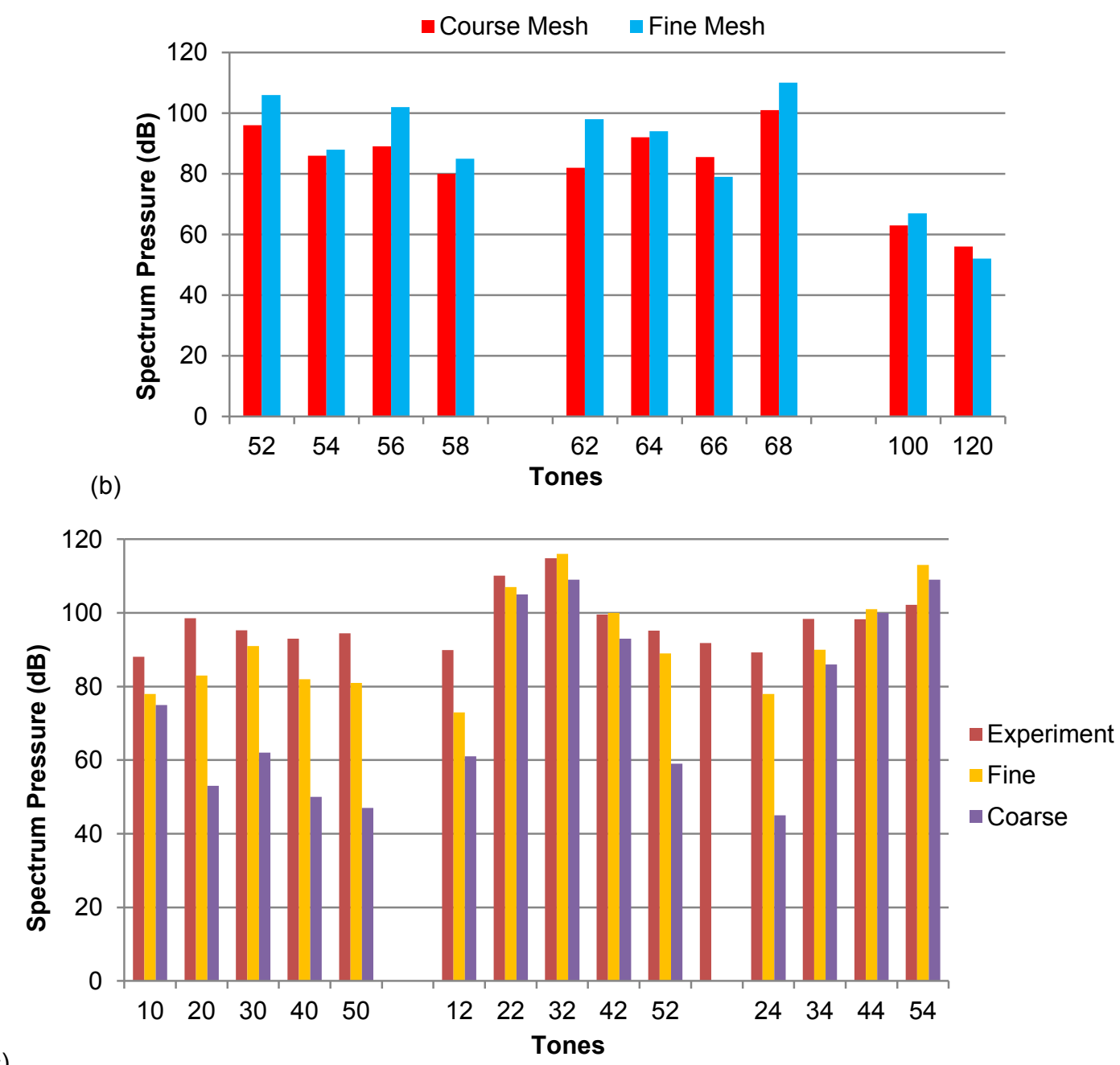

Figure 5.-(a) Experiment versus calculated acoustic tone levels using a coarse mesh at take-off conditions.

Microphone at $90^{\circ}$ and $1.5 \mathrm{~m}$ from centerline.(b) Mesh comparison at higher acoustic tones-course versus fine mesh. Microphone at $90^{\circ}$ and $1.5 \mathrm{~m}$ from centerline. (c) Experiment/fine mesh/coarse mesh calculations with the microphone located at $140^{\circ}$ and $1.5 \mathrm{~m}$. 


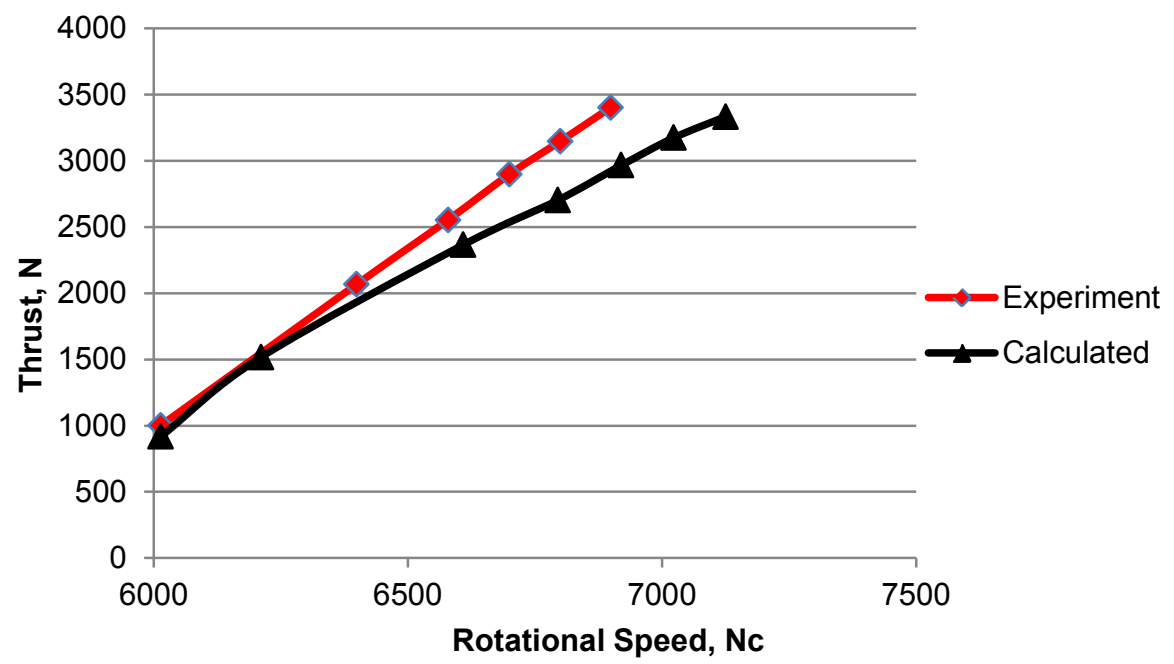

Figure 6.-Cruise condition (Mach no. 0.8) thrust versus corrected rotational speed (rpm). The experimental blade rotations were $64.4^{\circ}$ (forward) $/ 61.8^{\circ}$ (aft). Corrected speeds used static temperatures.

\section{Cruise Operating Conditions (Mach Number $=0.8$ )}

Figure 5 displays cruise condition thrust levels, experiment versus simulation. These results are reasonably close to the experimental data especially at the lower range of rpm. For the cruise calculations the forward and aft blades were rotated to match the experimental blade angles: $64.4^{\circ}$ forward and $61.8^{\circ}$ for the aft rotor.

The discrepancy between data and calculation at the higher rpm levels may be due to structural twisting of the blades as a functions of the rotational velocity. This discrepancy was not apparent for the take-off results, but the high speed blade pitch may better align with the rotational velocity which results in a more significant deformation.

\section{Summary}

The intent of this paper was to document aerodynamic performance and acoustic simulations of the F31/A31 open rotor geometry. This historical dataset is available as noted in Reference 4. Overall aerodynamic data was reasonably well predicted, with very good agreement seen at take-off conditions and less accurate predictions for cruise conditions. The initial fine mesh used in this analysis (16M nodes) was thought to be necessary for accurate acoustic predictions, however, very reasonable agreement was seen using a course mesh ( $2 \mathrm{M}$ nodes) at the $90^{\circ}$ side location. Noise measurements at the $140^{\circ}$ location were significantly more sensitive to mesh resolution. Overall, the aerodynamic and acoustic simulations matched experimental data reasonably well. Cruise operating point simulations may benefit additional studies that better match the experimental flowfield.

There were two unexpected results from this study. The first is that a steady-state model of rotor/rotor interations (NLH) was able to capture acoustic data to a reasonable extent. Future studies will examine if this finding remains true for advanced open rotor geometries and continues to provide reasonable estimates for high frequency interation tones. The second is that the cruise thrust results did not match as well as the take-off results. These unexpected findings will be studied in future efforts. 


\section{References}

1. "Blade Runner: GE's Quiet Progress on Open-Rotor," Aviation Week and Space Technology, December 14, 2009.

2. Hoff, G.E. et al.,"Experimental Performance and Acoustic Investigation of Modern, Counterrotating Blade Concepts, Final Report," NASA Contractor Report 185158, January 1990.

3. Van Zante, D., "An Open Rotor Test Case: F31/A31 Historical Baseline Blade Set," ISABE 20111310.

4. Deconinck, T., Capron, A., Barbieux, V., Hirsch, C., and Ghorbaniasl, G., "Sensitivity Study on Computational Parameters for the Prediction of Noise Generated by Counter-Rotating Open Rotors," AIAA-2011-2765.

5. Envia, E., personal communication, 2012.

6. Vilmin, S., Lorrain, E., Hirsch, CH., Swoboda, M., "Unsteady Flow Modeling Across the Rotor/Stator Interface Using the Nonlinear Harmonic Method," ASME GT2006-90210. 


\begin{tabular}{|c|c|c|}
\hline \multicolumn{2}{|c|}{ REPORT DOCUMENTATION PAGE } & $\begin{array}{l}\text { Form Approved } \\
\text { OMB No. 0704-0188 }\end{array}$ \\
\hline \multicolumn{3}{|c|}{ 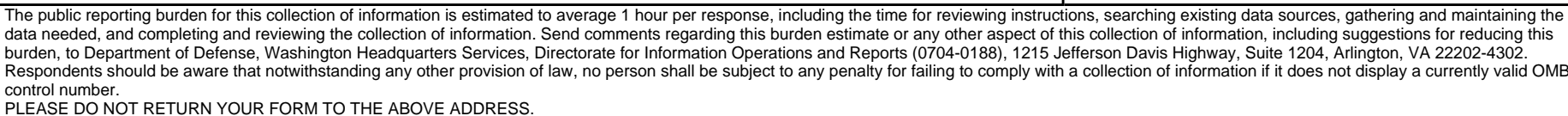 } \\
\hline $\begin{array}{l}\text { 1. REPORT DATE (DD-MM-YYYY) } \\
01-02-2013\end{array}$ & $\begin{array}{l}\text { 2. REPORT TYPE } \\
\text { Technical Memorandum }\end{array}$ & 3. DATES COVERED (From - To) \\
\hline \multirow{3}{*}{\multicolumn{2}{|c|}{$\begin{array}{l}\text { 4. TITLE AND SUBTITLE } \\
\text { Aeroacoustic and Performance Simulations of a Test Scale Open Ro }\end{array}$}} & 5a. CONTRACT NUMBER \\
\hline & & 5b. GRANT NUMBER \\
\hline & & 5c. PROGRAM ELEMENT NUMBER \\
\hline \multirow{3}{*}{\multicolumn{2}{|c|}{$\begin{array}{l}\text { 6. AUTHOR(S) } \\
\text { Claus, Russell, W. }\end{array}$}} & 5d. PROJECT NUMBER \\
\hline & & 5e. TASK NUMBER \\
\hline & & $\begin{array}{l}\text { 5f. WORK UNIT NUMBER } \\
\text { WBS 561581.02.08.03.13.13 }\end{array}$ \\
\hline \multicolumn{2}{|c|}{$\begin{array}{l}\text { 7. PERFORMING ORGANIZATION NAME(S) AND ADDRESS(ES) } \\
\text { National Aeronautics and Space Administration } \\
\text { John H. Glenn Research Center at Lewis Field } \\
\text { Cleveland, Ohio 44135-3191 }\end{array}$} & $\begin{array}{l}\text { 8. PERFORMING ORGANIZATION } \\
\text { REPORT NUMBER } \\
\text { E-18631 }\end{array}$ \\
\hline \multirow{2}{*}{\multicolumn{2}{|c|}{$\begin{array}{l}\text { 9. SPONSORING/MONITORING AGENCY NAME(S) AND ADDRESS(ES) } \\
\text { National Aeronautics and Space Administration } \\
\text { Washington, DC 20546-0001 }\end{array}$}} & $\begin{array}{l}\text { 10. SPONSORING/MONITOR'S } \\
\text { ACRONYM(S) } \\
\text { NASA }\end{array}$ \\
\hline & & $\begin{array}{l}\text { 11. SPONSORING/MONITORING } \\
\text { REPORT NUMBER } \\
\text { NASA/TM-2013-217707 }\end{array}$ \\
\hline \multicolumn{3}{|c|}{$\begin{array}{l}\text { 12. DISTRIBUTIONIAVAILABILITY STATEMENT } \\
\text { Unclassified-Unlimited } \\
\text { Subject Categories: } 05 \text { and } 07 \\
\text { Available electronically at http://www.sti.nasa.gov } \\
\text { This publication is available from the NASA Center for AeroSpace Information, 443-757-5802 }\end{array}$} \\
\hline
\end{tabular}

\section{SUPPLEMENTARY NOTES}

\section{ABSTRACT}

This paper explores a comparison between experimental data and numerical simulations of the historical baseline F31/A31 open rotor geometry. The experimental data were obtained at the NASA Glenn Research Center's Aeroacoustic facilty and include performance and noise information for a variety of flow speeds (matching take-off and cruise). The numerical simulations provide both performance and aeroaucostic results using the NUMECA's Fine-Turbo analysis code. A non-linear harmonic method is used to capture the rotor/rotor interaction.

\section{SUBJECT TERMS}

Propulsion; Simulation

\begin{tabular}{|c|c|c|c|c|}
\hline \multicolumn{3}{|c|}{ 16. SECURITY CLASSIFICATION OF: } & \multirow{2}{*}{$\begin{array}{l}\text { 17. LIMITATION OF } \\
\text { ABSTRACT } \\
\text { UU }\end{array}$} & \multirow{2}{*}{$\begin{array}{l}\text { 18. NUMBER } \\
\text { OF } \\
\text { PAGES } \\
16\end{array}$} \\
\hline $\begin{array}{l}\text { a. REPORT } \\
U\end{array}$ & $\begin{array}{l}\text { b. ABSTRACT } \\
U\end{array}$ & $\begin{array}{l}\text { c. THIS } \\
\text { PAGE } \\
\text { U }\end{array}$ & & \\
\hline
\end{tabular}



